\title{
Edición Extraordinaria.
}

Memorias del VIII Encuentro Nacional de Experiencias en Enseñanza de la Biología y la Educación Ambiental. III Congreso Nacional de Investigación en Enseñanza de la Biología.

\section{INVESTIGACIÓN NARRATIVA EN LA ENSEÑANZA DE LA BIOLOGÍA: POSIBILIDADES Y ASPECTOS CRUCIALES}

AUTORES:

Rebeca Urazán ${ }^{1}$, Nixon Medina Talero

"La vida no es la que uno vivió, sino la que uno recuerda, y cómo la recuerda para contarla”. Gabriel García Márquez.

\section{RESUMEN}

La investigación narrativa en educación, ha adquirido gran importancia debido a las posibilidades que presenta para comprender la práctica docente de una manera alternativa, dotándola de valor y dando voz a la experiencia.

Es desde este aspecto, que hemos desarrollado este texto, queriendo dar a conocer las posibilidades, que nosotros mismos hemos hallado en este tipo de investigación, para comprender el quehacer del profesor de ciencias (en especial de biología). Creemos, que al dar valor a la experiencia y relatos de los profesores, estamos reconociendo su papel como productores legítimos de conocimientos. Es rescatando la voz del profesor, como se empiezan a constituir nuevos escenarios para la dignificación de la profesión docente.

En esta ponencia, presentaremos algunas de las investigaciones por nosotros realizadas desde este ámbito. En este artículo de revisión procuraremos dar algunas pautas para tener en cuenta tanto en el desarrollo de este tipo de investigaciones, así como algunas posibilidades de análisis narrativo. Adicionalmente compartiremos algunas inferencias que hemos logrado en los relatos recolectados, en relación con la práctica docente e identidad versus formación inicial y continua.

PALABRAS CLAVE. Investigación narrativa, relatos, experiencia, saberes, enseñanza de la biología.

\section{ABSTRACT}

\footnotetext{
${ }^{1}$ Licenciada en Biología, Maestrante en Educación - Universidad Pedagógica Nacional de Colombia; rebeu16@hotmail.com.
} 2 Licenciado en Biología, Magister en Docencia- Universidad de la Salle ; nixonmedita@gmail.com 


\section{Edición Extraordinaria.}

\section{Memorias del VIII Encuentro Nacional de Experiencias en Enseñanza de la Biología y la Educación Ambiental. III Congreso Nacional de Investigación en Enseñanza de la Biología.}

Narrative research in education, has acquired great importance due to the possibilities presented to understand the teaching practice in an alternative manner, giving value and giving voice to the experience.

It is from this aspect, we have developed this text, wanting to present the possibilities that we have found ourselves in this kind of research, to understand the work of the science teacher (especially biology). We believe that by giving value to the experience and stories of teachers, are acknowledging their role as legitimate knowledge producers. He is rescuing the teacher's voice, as they begin to form new scenarios for the dignity of the teaching profession.

In this paper, we present some of the research conducted by us from this area. We will try to give some guidelines to take into account both the development of this type of research, as well as some possibilities of narrative analysis. Additionally we share some inferences we have achieved in the stories collected in relation to teaching practice and identity versus initial and continuing training.

KEYWORDS. Narrative inquiry, stories, experience, knowledge, teaching biology.

\section{INTRODUCCIÓN}

Siempre es un reto hablar de narrativas y sobre todo orientándolas a la investigación en la enseñanza de las ciencias naturales (Específicamente de biología). La razón es la complejidad epistemológica y ontológica que subyace a la investigación narrativa (narrative inquiry). La comprensión como conocimiento y la experiencia construida como una realidad es confrontante, sobre cuando en la enseñanza de las ciencias donde impera una percepción del deber ser como las ciencias naturales (Sánchez, Urazán y Neusa, 2014). Y es que el positivismo y la concepción de lo real como experimental, reproductible y real ha imperado en las ciencias naturales (y a su vez a la enseñanza de las ciencias)

Bachelard (2007) lo plantea de la siguiente forma, el autor considera que lo real es aquello que se nos plantea como lo que deberíamos ser pero que no somos, porque ¿quién podría decir con sus investigaciones que ha logrado captar absolutamente todo lo real?. Sin embargo, es esta noción (sobre la realidad) desde la que se ha movido las ciencias durante gran parte de su historia (desde que consideramos la ciencia como ciencia).

No obstante, aportando al anterior planteamiento, autores como Gadamer (1992) consideraron que nuestra sociedad está determinada por las concepciones sociales que poseemos de ella. Bolívar (2002), complementa la idea al pensar que "la narrativa no solo expresa importantes dimensiones de la experiencia vivida, sino que, más radicalmente, media la propia experiencias y configura la construcción social de la realidad" (Bolívar, 


\section{Edición Extraordinaria.}

\section{Memorias del VIII Encuentro Nacional de Experiencias en Enseñanza de la Biología y la Educación Ambiental. III Congreso Nacional de Investigación en Enseñanza de la Biología.}

2002, p. 4). Es decir, es la experiencia la que genera una constitución de lo real en nuestra sociedad. Y la investigación narrativa se concentra en recuperar la experiencia individual.

La investigación narrativa, no surge de la nada, sus orígenes están en el silencio. El silencio de aquellos sin voz o cuyas voces no eran tan importantes para ser escuchadas. La investigación hermenéutica interpretativa (base de la investigación narrativa) aparece hacia finales siglo XVIII, pero crece de manera significativa a principios del siglo XIX. (Erickson en Wittrock, 1989).

La raíz se encuentra en el interés por la vida de las personas sin voz en la sociedad, inicialmente campesinos, población proletaria y posteriormente en los habitantes urbanos. Aunque, especialmente en el ámbito de la investigación narrativa (Bolívar, 2006), la investigaciones ha procurado comprender procesos económicos, históricos y culturales de una sociedad. Su campo de aplicación principal se reconoce desde el ámbito de las ciencias sociales y de la antropología, desde donde más se ha estimulado la investigación en narrativas en Latinoamérica.

Sin embargo, a propósito de esa base de a investigación narrativa, creo importante señalar algo mencionado por Bolívar (2002, p. 7) cuando vincula lo narrativo a lo femenino, porque lo narrativa se identifica como una "forma específica del discurso femenino". Creo que esta concepción femenil de la narrativa, se relaciona con la represión histórica de la voz de la mujer, que al ser acallada, se reconstruyo más en historias que en escritos. La voz se constituye, entonces como una forma de conocimiento. Esa índole femenina del conocimiento, de manera tacita, dota de valores específicos a la investigación narrativa. Da un estatus diferente al asignado a la experiencia, siendo ella entonces legítima.

A propósito de esa vinculación de lo femenino con lo narrativo. Cevasco, (2006, p. 3) reconoce que el valor de lo femenino no solo se limita al discurso de la exclusión sino a la revaloración del otro, porque "celebra la irracionalidad, la naturaleza, el cuerpo y la intuición, como opuestos a la pretensiones de neutralidad de la cultura que los excluye". Para Bolívar (2002, p. 7), eso femenino a lo que se apela es el yo dialógico, que lejos de la pretensión de neutralidad "siente y ama, frente al modo dominante de discurso... (Uniforme, racionalista o pretendidamente neutro, propio de un extraterrestre asexuado es decir angélico)". La pretensión de objetividad o neutralidad, desde esta perspectiva (hermenéutica), no sería más que un argumento para obligar (un argumento de poder).

Y es que no debemos obviar que la diversidad de criterios de escucha y de praxis está presente en nuestra sociedad. No hay una sola verdad en el discurso, si no múltiples verdades en diversos discursos tal como lo planeta Maturana (1993). 


\title{
Edición Extraordinaria.
}

\author{
Memorias del VIII Encuentro Nacional de Experiencias en Enseñanza de la Biología y la \\ Educación Ambiental. III Congreso Nacional de Investigación en Enseñanza de la \\ Biología.
}

Más allá de los aspectos epistemológicos que forman la investigación narrativa en contraposición con lo paradigmático y positivista, que investigadores como Bolívar (2002; 2006) desarrollan de una manera magistral y que anteriormente se mencionó de manera somera. Quiero profundizar en esta ponencia en otros aspectos de la investigación narrativa (Específicamente en sus posibilidades para reconocer las prácticas de los profesores de biología). Así que proseguiremos el orden de este discurso, no sin antes señalar que sin una mínima aproximación a esa distinción epistemológica de la narrativa es imposible hallar en ella su real profundidad.

Dando continuidad, es prioritario en la investigación narrativa el hecho de la palabra y esa palabra usualmente constituye una experiencia. No se trata solo de hablar de cosas diversas, sino de construir una experiencia, a esa construcción mínima de sentido sobre un aspecto específico (usualmente un problema) se le llama relato. Este tipo de investigación narrativa se sustenta sobre los relatos de experiencias.

Hleap (2004, p.7) define el relato como "una totalidad significante, su especificidad comunicativa obliga a una coherencia, una legibilidad, un orden en la exposición, que le da a la vez un orden, un sentido a lo vivido (generalmente de manera caótica) en la experiencia". Podríamos reconocer entonces el relato como la forma en que se presenta la experiencia. Imaginémoslo como un cuerpo de la praxis (del vivir). El cuerpo es constituido por el que relata, por eso una misma experiencia puede poseer diversos cuerpos.

Actualmente, los relatos sobre la enseñanza se han tornado importantes en la investigación educativa. La investigación narrativa ha hallado un lugar preponderante en la investigación en Latinoamérica siendo Argentina y Brasil quienes mayores adelantos han logrado en este aspecto. Es así que investigadores como Suarez (2005) han constituido una historia de la educación formada desde las voces de los profesores, siendo impulsado así el valor de lo narrativo como posibilidad para la reconstrucción histórica y de identidad docente. Porque no hablábamos solo de la construcción de relatos sobre lo que realiza el profesor por parte de agente externos a la educación, sino estamos considerando como valida las voces de los actores que hacen parte de lo que es educar.

Suarez (2008), propone entonces no solo construir una historia, sino comprender que la historia que se ha construido tiene un valor práctico. Según Carr y Kemmis (1988, p. 20) "si la investigación educativa ha de comprometerse totalmente con la investigación de los problemas educacionales, tendrá que basarse en la convicción de que la única fuente auténtica de las teorías y los saberes en materia de educación son las experiencias prácticas de donde derivan esos problemas, y que la misión propia de la investigación educativa 


\title{
Edición Extraordinaria.
}

\author{
Memorias del VIII Encuentro Nacional de Experiencias en Enseñanza de la Biología y la \\ Educación Ambiental. III Congreso Nacional de Investigación en Enseñanza de la \\ Biología.
}

consiste en formular teorías basadas en la realidad de la práctica educativa". Se trata de aprende de esos discursos constituidos, ponerlos en conversación comprendiendo el valor del otro y sobre todo que sea el profesor un legitimo constructor de saberes didácticos y pedagógicos, que como plantean Carr y Kemmis (1988) sea esa experiencia del profesor la fuente de las teorías y saberes. La investigación narrativa nos brinda esa oportunidad.

Es por ello que consideramos muy importante el desarrollo de la investigación narrativa en la comprensión de los saberes que se han construido sobre la enseñanza de la biología y la identidad que como enseñantes poseen los profesores de biología.

\section{MetOdOLOGÍA}

Al comprender esas posibilidades que se hallan en la investigación narrativa, hemos querido indagar sobre las investigaciones narrativas que se han desarrollado en el ámbito de la enseñanza de la biología hallando que no son múltiples y en su mayoría se encuentran en pregrado (Medina, 2014). Por otra parte hay que hacer una aclaración y es que existen investigaciones sobre la acción narrativa y otras sobre investigación narrativa (Connelly y Clandinin, 1995). Por nuestro parte nos concentramos en la segundas.

En estos últimos dos años hemos desarrollado diversas investigaciones narrativas (Medina, 2014; Medina, Siciliani y Urazán, 2014; Urazán y Soto, 2014; Urazán y Medina, N.D), fundamentado el análisis narrativo desde las categorías planteadas por Marguerat y Bourquin (2006), Ska, Sonnet \& Wénin (2001) y Bolívar (2001). El tema central de los relatos adquiridos se ha dirigido a indagar como la formación inicial y permanente del profesorado ha incidido la construcción de su saber y su influencia en su quehacer. Las categorías son

El proceso metodológico de investigación narrativa, inicia precisamente con la selección de un tema central desde el que se orientara la construcción del relato. Esa temática, claramente está sustentada en una juiciosa revisión sobre la temática. Dando así lugar a una entrevista semiestructurada. Para lo que recomendamos realizar una revisión pausada de las implicaciones que tiene la construcción de esa entrevista (Elliot, 1990)

Para esta entrevista semiestructurada es posible generar algunas categorías previas, en como propone Bolívar y Domingo (2006), en nuestro caso han sido tradición del oficio, practica profesional y reflexión. Autores como Hleap (2004) propone al contrario desarrollar categorías mediante el relato. Desde estas categorías se construyeron cuarenta preguntas. 


\title{
Edición Extraordinaria.
}

\author{
Memorias del VIII Encuentro Nacional de Experiencias en Enseñanza de la Biología y la \\ Educación Ambiental. III Congreso Nacional de Investigación en Enseñanza de la \\ Biología.
}

Consecutivamente, en el caso de las investigación de maestría de Medina (2014) se tomaron entrevistas a profesores expertos (en su mayoría profesores de biología) con más de quince años de experiencia (la mayoría de los profesores cumplían más de veinte años de experiencia), todos de instituciones publica de Bogotá del área de ciencias naturales. Para el caso de la investigación de Urazán y Soto (2014) los profesores eran profesores noveles (licenciados en biología egresados de la misma universidad y pretendientes a un mismo grupo de investigación), no superando 5 años de experiencia tanto en instituciones públicas como privadas. En estos dos casos hubo una preponderancia de los temas en relación a la formación inicial y continua en relación a la práctica docente.

Posterior a las entrevistas, se realizo la transcripción y análisis; que implico reconocer las categorías emergentes o en el caso de la tesis de Medina (2014) se exploro el uso de herramientas de análisis propuestas por Marguerat y Bourquin (2006) para su análisis, respetándose así la integridad del discurso.

\section{DisCUSIÓN}

En estas investigaciones hay un elemento común inicial y es la importancia que los maestros otorgan a ser escuchados. En algunos de las narraciones los profesores (sobre todo los experimentados) nos comentaron como esa era la primera vez que realizaban un recuento de su propia practica, siendo para ellos un proceso confrontante. Y es que como planeta Bolívar y Domingo (2006, p. 32) no es fácil contarse, porque "lo que somos depende del modo en que nos comprendemos y construimos textos sobre nosotros mismos", es esa la razón de la dificultad que encuentran los profesores al relatarse a sí mismos (o a su historia).

En el relato existieron no solo palabras, sino gestos, lágrimas, risas y toda clase de expresiones que señalan la importancia que tiene la construcción de su propia experiencia. Además como esa historia del ser maestro y de su constitución como maestro, no solo se limita a las experiencia del aula del clase sino que esa aula de clase ha marcado emocional, cultura y socialmente a los maestros. Como puntos comunes en las investigaciones se ha hecho evidente categorías como el traspaso generacional (el surgimiento de nuevos maestros, traspaso del oficio), la gratificación emocional de la labor docente y los retos en el encuentro con los otros (estudiantes y maestros).

Contar su historia (como todo acto narrativo no es una acción lineal) (Marguerat y Bourquin ,2006), sino una acción en que un relato contenía microrelatos inmersos en un relato más grande, es decir que una historia estaba constituida de múltiples historias. Muchas de esos relatos se orientaban por un problema o reto que los profesores debían resolver, los 


\section{Edición Extraordinaria.}

\section{Memorias del VIII Encuentro Nacional de Experiencias en Enseñanza de la Biología y la Educación Ambiental. III Congreso Nacional de Investigación en Enseñanza de la Biología.}

momentos cruciales eran importantes en la constitución del profesional que eran esos profesores. Ellos mismos lo exponían al contar su relato y realizar una moraleja al finalizar la historia (sin haberlo preguntado). Era una especie de proceso introspectivo.

Y es que según Cruz (2010, p. 29) “el poder cognitivo de la narrativización confiere a los relatos una fuerza tal que los sitúa en un lugar intermedio de elaboración entre el conocimiento práctico personal y aquel otro conocimiento de orden superior que confiere estatus profesional a la actividad docente". Por eso siempre el relato concluía con una moraleja o lo que llamaríamos nosotros una anotación reflexiva que había influido en su práctica.

Por ejemplo una profesora nos contaba la historia de un accidente en un laboratorio durante su formación inicial, en el cual había estado a punto de provocar un incendio, en razón de ello siempre que iniciaba clases por primera vez en laboratorio usualmente contaba a sus estudiantes esa historia. Al finalizar esa historia la profesora realiza la siguiente reflexión:

\footnotetext{
"Pero a todos como experiencia, a todo el grupito, con el que yo estaba en ese momento, digamos, nos quedó como experiencia nunca más volver a hacer cosas que no correspondían, y creo que, por lo menos para mí, como lección y que le transmito a mis estudiantes es lo importante que es saber escuchar y seguir indicaciones y tratar de hacer las cosas lo más correctas posibles y como a veces, digamos una imprudencia de esas, podría costarnos hasta la vida de las personas. Entonces sobretodo esa fue la experiencia pues bastante significativa" ${ }^{3}$.
}

No obstante, es importante sugerir que durante la entrevista se deben cuidar los relatos que se generan, porque es común que ese afán por el hallar la moraleja se terminen devastando los relatos y sean llevados a una serie de opiniones, pero no a relatos. Un relato se asocia a una experiencia (Hleap, 2004), por lo tanto tiene una presentación del momento, un desarrollo de la historia, una finalización de la misma y finalmente una moraleja o acción reflexiva sobre la acción (Aunque esto no siempre ocurre, a veces solo se conecta a otra historia) (Medina, 2014).

Para evitar la problemática anteriormente descrita, proponemos inducir preguntas que aunque estén fuera de la estructura de la entrevista semiestructurada lleven a un detonante narrativo, reconociéndolo como ese momento cero (un punto para decisiones, momento de confrontación, inicio de nuevas etapas, problemáticas en el aula, vinculación afectiva, nuevos espacios o saltos en el tiempo narrativo) Marguerat y Bourquin (2006).

Para el análisis narrativo según Siciliani (2009, p.31) es preponderante el estudio del tiempo interrogándolo en cuatro dimensiones, "el momento, la velocidad, la frecuencia y el orden", la importancia de este elemento puede observarse en la extensión por ejemplo de un hecho

\footnotetext{
${ }^{3}$ Fragmento de Narración Myriam, Narración completa en Medina, 2014.
} 


\section{Edición Extraordinaria.}

\section{Memorias del VIII Encuentro Nacional de Experiencias en Enseñanza de la Biología y la Educación Ambiental. III Congreso Nacional de Investigación en Enseñanza de la Biología.}

que puede ser narrado en varias páginas, por ejemplo en el narrar una experiencia sobre el primer día de clases que en muchos de los casos analizados ocupo varias páginas, y posterior a ese momento los profesores (De más experiencia) realizaban grande saltos de tiempo, es decir narraban esa primera experiencia y luego en un párrafo pasaban por alto dos o tres años. Eso habla de la evidencia de los cambios de tiempo, en relación a momentos de interés. Por ejemplo durante las narraciones un profesor nos hablo en solo cuatro párrafos de su formación inicial, no quiso referirse más al tema aunque tratamos de hallar detonantes narrativos, sin embargo, realizo un gran relato de su formación posgradual y como influía esa formación en el desarrollo de cada una de sus clases de genética.

Otro aspecto importante para la lectura narrativa es el hecho de pensar los personajes, estos actores de un relato (en los que le mismo profesor se incluye como personaje) pueden tener diferente tipos de señalamientos simbólicos (ej: amigos o contrincantes). Adicionalmente es importante pensar en elementos como: "voz narrativa que emplea una serie de herramientas como el abismado, simbolismo, ironía, reseña histórica y glosa explicativa. La perspectiva o punto de vista que tiende su mirada sobre las diferentes focalizaciones que emplea el relato. La posición del lector frente al relato en la medida de la cantidad de información que maneja narrador y narratario" (Medina, Sicialini y Urazán, 2014).

\subsection{EL PROFESOR DE BIOLOGÍA EN SUS PROPIAS NARRATIVAS}

Seria, a nuestro modo de ver imposible exponer en este texto los aspectos que sobre sí mismos cuentan los profesores en más de ocho narrativas (que hemos desarrollado hasta este momento y en las que nos encontramos en elaboración), pero en general mencionaremos dos aspectos. Primero el profesor de biología en su identidad se ve como un sujeto que constituye personas, es decir no solo hay una preocupación legítima por transmisión de saberes sino por la formación para la vida. El maestro de biología no solo se lee desde lo disciplinar sino desde las posibilidades de devenir con el otro:

\footnotetext{
"Y ya hablé con la mamá y le dije "encáusele y verá que llegará lejos y se acordará de mí", yo donde pongo el ojo pongo... y le digo mi científico. Y eso es lo que Yo quiero, a los chicos yo los pienso a largo plazo, por allá en su Universidad, en sus trabajos, en su vida como pareja, en sus hogares" (énfasis puesto por los autores).
}

Segundo, una identidad en que la experticia revela lo valioso del acto de educar (Martinez, 2008). El valor de comprender que hay posibilidades de ser al enseñar:

"Yo quiero que los que escuchen o lean esta entrevista no sientan tristeza, los profesores que están empezando su carrera como docentes que están enfrentando, porque ahorita hay mucha problemática ... pero que piensen que es la mejor profesión, iLa mejor del mundo!" ${ }^{4}$

\section{CONCLUSIÓN}

\footnotetext{
${ }^{4}$ Fragmento de Narración Pilar, Narración completa en Medina, 2014.
} 


\section{Edición Extraordinaria.}

\section{Memorias del VIII Encuentro Nacional de Experiencias en Enseñanza de la Biología y la Educación Ambiental. III Congreso Nacional de Investigación en Enseñanza de la Biología.}

La investigación narrativa se constituye como un factor determinante para aportar a la formación de la identidad docente del maestro de biología, en ella hay grande posibilidades de leeremos en nuestro ejercicio, siendo comprendidos como sujetos integrales.

Además, se constituye como un escenario que posibilita la producción de un saber que le es propio al docente en ejercicio, es decir, se le reconoce como un intelectual.

\section{REFERENCIAS BIBLIOGRÁFICAS}

- Bolivar, A. \&\& Domingo, J. (2006). La Investigación Biográfica y Narrativa en Iberoamérica: Campos de desarrollo y estado actual. Forum: Qualitative Social Research, 7 (4), 1-33.

- Bolívar, A. (2001). La investigación biográfico-narrativa en educación. Enfoque y Metodología. Madrid, España: La Murralla.

- Bolivar, A. (2002). ¿De nobis ipsis silemus?. Epistemologia de la Investigación Biografico-narrativa en educación. Revista Electronica de Investigación Eduactiva, 4 (1), 1-25.

- Bolívar, A., Domingo, J. \& Fernández, M. (2006). La Investigación Biografico- Narrativa en Educación: Enfoque y Metodología. Madrid, España: Editorial La Muralla.

- Carr, W. \&e Kemmis, S. (1988). Teoría Crítica de la Enseñanza. Barcelona, España: Ediciones Martínez Roca.

- Cevasco, R. (2006) De Freud a Lacan, la cuestión femenina Recuperado de: http://www.psicoanalisisysociedad.org/Textos/Freud-Lacan-femeninaRCevasco.pdf

- Connelly, F. M. \& Clandinin, D. J. (1995). Relatos de experiencia e investigación narrativa. En Larrosa, J. et al. (Eds), Déjame que te cuente. Ensayos sobre narrativa y educación. Barcelona, España: Laertes.

- Cruz, M. (2010). Aproximación Biográfico- Narrativa a la Investigación sobre Formación Docente Revista de Curriculum y Formación del Profesorado, 14 (3), 17-32.

- Erickson, F. (1989). Métodos Cualitativos de Investigación sobre la Enseñanza. En: Wittrock, M. (comp.) La investigación de la enseñanza, II. Métodos Cualitativos y de Observación. España: Paidós.

- Gadamer, H.G. (1992) Verdad y Método (Tomo II). España: Editorial Sigueme.

- Hleap, J. (2004). Sistematizando Experiencias Educativas. Colombia: Universidad del Valle

- Marguerat, D. \& Bourquin, Y. (2000). Como leer los relatos bíblicos: Iniciación al análisis narrativo. España: Editorial Sal Terrae.

- Martínez, M.C. (2008). Fuerzas, Movimientos e Imágenes que han Configurado los Modos de ser Maestro en Colombia. En Martínez, M. C. (Eds), Redes Pedagógicas y Constitución del Maestro como Sujeto Político (pp. 39-69) . Bogotá, Colombia: Editorial Magisterio.

- $\quad$ Maturana H, (2002); La Objetividad: Un Argumento para Obligar. España: Dolmen Ediciones.

- Medina, N., Siciliani, JM., \&e Urazán, R. (2014). El Análisis Narrativo: La Propuesta de Marguerat y Bourquin Aplicada a la Investigación Educativa. Revista Ciencia y Tecnica, Numero Extraordinario, mesa 70. Recuperado de: http://www.21.edu.ar/investigacion-ponencias-congreso-investigacion-cualitativa-ciencias-sociales.html

- Medina, N.A. (2014). Reconstrucción del Saber Pedagógico a Través de la Interpretación Biográfico-Narrativa de Relatos de Cinco Profesores del Distrito del Área de Ciencias Naturales y Educación Ambiental con más de 20 Años de Trayectoria Profesional. (Tesis Maestría). Universidad de la Salle. Bogotá, Colombia 


\section{Edición Extraordinaria.}

\section{Memorias del VIII Encuentro Nacional de Experiencias en Enseñanza de la Biología y la Educación Ambiental. III Congreso Nacional de Investigación en Enseñanza de la Biología.}

- Perafán, G. A. (2013). La transposición didáctica como estatuto epistemológico fundante de los saberes académicos del profesor. Folios, 37, 83-93. Recuperado de: http://revistas.pedagogica.edu.co/index.php/RF/article/view/1822/1794

- Sánchez, D., Urazán, R. \& y Neusa, C. (2014). Hacia la Comprensión del Papel de la Investigación Cualitativa en la Enseñanza de las Ciencias Naturales. Revista Ciencia y Tecnica, Numero Extraordinario, mesa 32. Recuperado de: http://www.21.edu.ar/investigacion-ponencias-congreso-investigacion-cualitativa-ciencias-sociales.html

- Siciliani, J.M. (2009). Teología Narrativa. Colombia: Ediciones Unisalle.

- $\quad$ Ska, J.L., Sonnet, J.P., \& Wénin, A. (2001). Análisis narrativo de relatos del Antiguo Testamento. España: Editorial Verbo Divino.

- $\quad$ Stake, R. (1999). Investigación con Estudio de Casos. Segunda edición, Madrid: Morata.

- Suarez, D. (2008). La Tradición Crítica en Educación y Reconstrucción de la Pedagogía. En: Elisalde, R. \& Ampudia, M. (comp.) Movimientos Sociales y educación: Teoría o historia de la educación popular en América Latina. Buenos Aires: Buenos Libros.

- Suárez, D., Ochoa, L., \& Maddoni, P. (2005). La documentación narrativa deexperiencias pedagógicas: Una estrategia para la formación de docentes. Recuperado de:http://www.porlainclusion.educ.ar/documentos/La_documentacion_narrativa_de_experiencias_pedagogicas.p df

- Urazán, R. \& Soto, R. S. (2014). El papel de los Semilleros de Investigación (como redes de docentes) durante la formación inicial, en la práctica pedagógica de docentes en ejercicio. Aproximación narrativa. Congreso Adbia 2014. Recuperado de: http://congresosadbia.com/ocs/index.php/roca2014/roca2014/paper/viewFile/875/463

- Urazán, R. \& Medina, N. A. (N.D) Momentos de Ruptura-Oportunidades de Creación. Narrativas sobre Prácticas Pedagógicas Alternativas en una Docente de Ciencias Naturales. (Articulo inédito) Universidad Pedagógica Nacional, Bogotá. 